\title{
OBJETIVACIÓN Y RACIONALIDAD DE LA CONCEPCIÓN DE LA RELIGIÓN EN LA FILOSOFÍA DE IMMANUEL KANT
}

\author{
Objectivity and Rationality of the Conception of Religion in \\ The Philosophy of Immanuel Kant
}

Oscar Edmundo Yangali Núñez ${ }^{1}$

\begin{abstract}
RESUMEN
Frecuentemente se afirma de modo presunto en la filosofía de Kant sobre límites de la metafísica olvidándose que los mismos nos sirven sobre todo para el conocimiento científico. En el presente trabajo propongo desarrollar cómo la crítica que expone Kant para establecer una metafísica trascendental y los límites de la ciencia nos conducen hacia una racionalización de la moral y, seguidamente, de la religión. En primer lugar, con base en la Crítica de la Razón Pura examino la condición de posibilidad de toda experiencia y conocimiento. En segundo lugar, analizo la relación entre la apercepción trascendental respecto de las ideas incondicionadas y la imposibilidad de su comprobación. Y, finalmente busco justificar cómo a pesar de ello, partiendo de un análisis de la ley moral, no se deriva sino un concepto de religión más racional.
\end{abstract}

\section{Palabras clave:}

Experiencia, racionalidad, ciencia, moral, religión.

\begin{abstract}
Frecuently, the limits of metaphysics in Kant's philosophy are remarked upon in a presumed mode, forgetting that they are useful to us, especially for scientific knowledge. In this paper I intend to develop how the critique that Kant exposes to establish a transcendental metaphysics and the limits of science leads to a rationalization of morality and, then, of religion. First, based on the Critique of Pure Reason he examines the condition of possibility of all experience and knowledge. Second, I analyze the relationship between the transcendental apperception with respect to the unconditional ideas and the impossibility of their verification. Finally, I seek to justify how, despite of the above, from an analysis of the moral law, nothing follows but a concept of a more rational religion.
\end{abstract}

\section{Keywords:}

Experience, rationality, science, moral, religion..

Docente de la Universidad Femenina del Sagrado Corazón y del Seminario Mayor Diocesano San José de Lurín: oscaryangali87@gmail.com / oscaryangalin@unife.edu.pe 


\section{INTRODUCCIÓN}

¿Es la filosofía de Kant una crítica exclusivamente de la metafísica? ¿Acaso esta crítica significaría un derrumbe de la metafísica en general en favor de un exclusivo discurso científico? Y así, ¿es acaso la filosofía de Kant un rechazo de la creencia religiosa debido a la imposibilidad de comprobación de la existencia de un Dios a cambio de un conocimiento del mundo sin más? Estas son preguntas que muchas veces nos hacemos con frecuencia respecto de la filosofía propuesta por Kant, ya que puede pensarse entre muchos lectores que nuestro filósofo al señalar que no es posible probar la existencia de un ser divino y que, por tanto, la metafísica tiene límites respecto de estos temas, se acaba entonces por fin toda pretensión de conocimiento que no sea científico y que pueda vincularse hacia algo relativo a lo religioso en nuestro autor.

A esto, sostengo que en el pensamiento de Kant no sólo esta lectura encuentra como punto de partida una interpretación equivocada, sino que, por el contrario, Kant mismo desarrolla un doble esfuerzo: si bien defiende que no es posible que la metafísica adopte postulados dogmáticos especulativos como punto de partida de sus investigaciones, también defenderá que, pese a lo anterior, la religión no carece de contenido racional, si bien debe ser considerada aparte de la metafísica. Esto hace que, a su vez, el trabajo de Kant mantenga una vigencia de lo que podemos comprender por medio del concepto de religión independientemente de nuestras creencias.

\section{SENSIBILIDADYENTENDIMIENTO: CONDICIONES DE POSIBILIDAD DE LA EXPERIENCIA}

Primero, hay que examinar el contexto de la articulación de todo tipo de conocimiento según Kant. Y es que en la Crítica de la Razón Pura encontramos las bases de dicho sistema de conocimiento, el cual lejos de apostar por un conocimiento exclusivamente independiente de todo dogmatismo metafísico, también apuesta por alejarse de la pretensión de un saber científico que olvide cuáles son sus presupuestos más fundamentales. Será, entonces, el conocimiento científico el que sea susceptible de la crítica de sus límites y no tanto la metafísica en general.

Para Kant, el conocimiento se adquiere no sólo por medio de la experiencia, sino que interviene en él algo que él mismo produce. Acerca del conocimiento señala Kant:

No hay duda alguna de que todo nuestro conocimiento comienza con la experiencia. Pues ċcómo podría ser despertada a actuar la facultad de conocer sino mediante objetos que afectan a nuestros sentidos y que ora producen por sí mismos representaciones, ora ponen en movimiento la capacidad del entendimiento para comparar estas representaciones, para enlazarlas o separarlas y para elaborar de este modo la materia bruta de las impresiones sensibles con vistas a un conocimiento de los objetos denominado experiencia? Por consiguiente, en el orden temporal, ningún conocimiento precede a la experiencia y todo conocimiento comienza con ella.

Pero, aunque todo nuestro conocimiento empiece con la experiencia, no por eso procede todo él de la experiencia. En efecto, podría ocurrir que nuestro mismo 
conocimiento empírico fuera una composición de lo que recibimos mediante las impresiones y de lo que nuestra propia facultad de conocer produce (simplemente motivada por las impresiones) a partir de sí misma. (Kant, 2007, pp. 41-42)

Con estas palabras comienza la introducción que escribe Kant en su Crítica de la razón pura con la finalidad de señalar que nuestros conocimientos requieren en una primera instancia de la experiencia, pues no habría otra manera de cómo nos veríamos afectados por los objetos sino por medio de los sentidos los cuales generan nuestras representaciones, de modo que nuestro entendimiento las compare y relacione con miras al conocimiento. Sin embargo, no podemos decir que todo él provenga de la experiencia, ya que nuestro conocimiento no sólo podría provenir de una fuente externa sino de lo que nosotros mismos somos necesariamente capaces de construir o producir.

Para Kant es seguro que estamos en posesión de ciertos conocimientos a priori en nuestro entendimiento (Kant, 2007, p. 43), i.e. de conocimientos que son independientes de la experiencia. Por ejemplo, en las matemáticas, ya que en ellas hablamos de conocimientos necesarios y universales para los cuales no requerimos tener intuición empírica alguna, sino que nuestro entendimiento es capaz por sí solo de comprenderlas debido a su necesidad y universalidad (Kant, 2007, p. 44). Luego, Kant considerará que estos principios de necesidad y universalidad, los cuales son principios puros a priori, serán indispensables para que sea posible la experiencia misma (Kant, 2007, p. 44).
¿Cómo es posible desarrollar esta tesis? En la Crítica de la razón pura Kant señala que nuestra capacidad de recibir representaciones, el ser afectados por los objetos, se llama sensibilidad, siendo ésta la que nos suministra las intuiciones; mientras que por medio del entendimiento es que los objetos son pensados, y es ahí de donde proceden nuestros conceptos (Kant, 2007, p. 65). Así, toda intuición empírica de un objeto indeterminado ${ }^{2}$ se llama fenómeno (Kant, 2007, p. 66), ya que consistirá en una representación del noúmeno tal como se nos aparece, pero dejándolo como algo incognoscible en sí para nosotros (Kant, 2007, p. 22). Según Kant, nosotros no conocemos las cosas en sí, sino las cosas como se nos aparecen, es decir, en cuanto fenómenos.

Ahora bien, respecto del fenómeno, Kant señala que su materia será su contenido referido a la sensación, mientras que la forma del fenómeno será aquello que hace que lo diverso del mismo pueda ser ordenado bajo ciertas relaciones, y que, por ello, la materia de todo fenómeno nos viene dada sólo a posteriori mientras que la forma del fenómeno debe encontrarse completamente a priori, conforme al conjunto de sensaciones ordenadas en el psiquismo, porque para Kant la sensibilidad misma ya es un principio a priori para cualquier representación (Kant, 2007, p. 66). La sensibilidad es la condición de posibilidad de la representación. Es respecto de este punto en el que Kant desarrolla su estética trascendental, donde básicamente sostiene también que la coordinación de todo el mundo sensible se encuentra mediado por los conceptos de espacio y tiempo. Y esto puesto que son dos conceptos puros mediante los cuales le damos estas condiciones de

2 O de una "cosa en sí", lo que equivale para Kant a un "noúmeno".

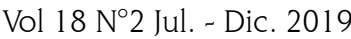


posibilidad a priori a todos los objetos un lugar y una sucesión. ${ }^{3}$ Y es que para Kant esta Crítica tratará de establecer la condición de posibilidad de toda experiencia humana. Por ello nos dice:

De todo lo anterior se desprende la idea de una ciencia especial que puede llamarse la Crítica de la razón pura, ya que razón es la facultad que proporciona los principios del conocimiento a priori.

De ahí que razón pura sea aquella que contiene los principios mediante los cuales conocemos algo absolutamente a priori. (Kant, 2007, p. 57)

Para Kant la razón humana es la que provee los principios de todo conocimiento a priori, es decir, el hombre posee antes que cualquier experiencia la condición de posibilidad de todo conocimiento en general desde su razón. Por este motivo, según Kant, también nos encontramos en la posibilidad de conocer algo absolutamente independiente de la experiencia.

El hombre puede examinar su razón y debe hacerlo, pues es necesario clarificarla y así preservarla de cometer errores a base de posibles excesos; y, por esta razón, es que Kant pretende desarrollar una filosofía que llama trascendental. Esto es, una filosofía o "conocimiento que se ocupa, no tanto de los objetos, cuanto de nuestro modo de conocerlos, en cuanto que tal modo ha de ser posible a priori" (Kant, 2007, p. 58). Una filosofía que asuma antes que nada la condición de posibilidad de los objetos y nuestro modo de aproximarnos a ellos. Y esto, porque para Kant: "el objeto no es aquí la naturaleza de las cosas, que es inagotable, sino el entendimiento que enjuicia esa naturaleza de las cosas y, además, con la particularidad de ser el entendimiento únicamente referido a su conocimiento a priori" (Kant, 2007, p. 59). Es decir, nuestra filosofía no aspirará a agotar la naturaleza de las cosas pues no podría jamás comprehenderla, sino que nuestra filosofía atenderá a nuestro modo de comprender a los objetos desde las posibilidades de nuestro entendimiento. Por una filosofía trascendental Kant entiende, entonces, un conocimiento que es consciente de la condición de posibilidad a priori de los objetos en la medida en que se nos dan como se nos aparecen, pero no asumiéndolos como creemos que se nos dan como cosas en sí.

La filosofía trascendental tiene la ventaja -y también la obligaciónde buscar sus conceptos de acuerdo con un principio, ya que salen puros y sin mezcla del entendimiento en cuanto unidad absoluta y, consiguientemente, deben estar interrelacionados, a su vez, de acuerdo con un concepto o una idea. (Kant, 2007, p. 104)

Una filosofía trascendental enseña que los conceptos del entendimiento provienen de él como principios que se refieren a unidades absolutas. De aquí derivamos nuestros conceptos o ideas.

La intuición es diversa pues tiene muchos objetos a su disposición, pero la intuición sintetiza a priori esta diversidad por medio de la imaginación; pero son los conceptos los que dan unidad a esa síntesis que realizamos y la representamos como lo que conocemos de un objeto

No pretendo en el presente trabajo desarrollar la concepción kantiana sobre estos conceptos puros por motivos de extensión. En todo caso, baste señalar o tener presente que estos conceptos puros no son empíricos pues no son obtenidos por ninguna experiencia, sino que son anteriores a cualquiera de ellas respecto de los objetos y por ello son a priori o condición de posibilidad de cualquier experiencia. 
(Kant, 2007, p. 112). Así, según Kant, estos conceptos puros del entendimiento los aplicamos a priori a los objetos a modo de representaciones o conceptos de las cosas (Kant, 2007, p. 113).

Cabe decir que, para Kant, en todo conocimiento de un objeto tiene que haber unidad de concepto, y esta unidad será parte de la condición de posibilidad a priori de todo nuestro conocimiento de los objetos en general. De otra manera no sería posible pensar las cosas en cuanto unidades. Así, podemos decir que para Kant nuestros conocimientos surgen de la experiencia, pero no considerada como la autora exclusiva de la información obtenida, la representación, sino que nosotros mismos poseemos la facultad de construirla a priori pues nuestra razón es la condición de posibilidad de toda experiencia ${ }^{4}$. La experiencia sólo es posible mediante la conjunción de la sensibilidad con el entendimiento. No es la experiencia posible independientemente del ejercicio de nuestra razón. Es decir, las condiciones de posibilidad a priori son las que fundan la experiencia, no al revés, he ahí la función de una metafísica trascendental. Nos dice por ello Dufrenne: "el a priori adquiere un nuevo sentido: designa a la vez una condición formal de la experiencia y una condición surgida de la naturaleza subjetiva del espíritu; una ley que el espíritu impone a la naturaleza porque es asignada a su propia naturaleza (...)" (Dufrenne, 2010, p. 23). Precisamente, por estos motivos la metafísica trascendental que funda Kant no será una ciencia más sino un discurso sobre la ciencia, pues no es posible dirigirnos a la relación entre la ciencia y la razón humana sino por medio del examen de las condiciones de posibilidad a priori de toda experiencia, $\mathrm{y}$, por tanto, del conocimiento científico.

En este sentido, los límites del conocimiento a los que se refiere Kant con esta Crítica apuntarán sobre todo al saber científico más que al conocimiento metafísico, pues vemos que es posible fundar una metafísica trascendental que no sólo supere los dogmatismos especulativos, sino que también nos prevenga de que éstos se inmiscuyan en nuestros conocimientos científicos. Lo que concebimos como conocimiento de nuestro mundo no proviene como tal sino de la razón. No podremos saber a ciencia cierta que el mundo sea el que nos provea de conocimientos que consideraremos necesarios y universales para nuestras ciencias. Será, por tanto, la razón la que aporta dicha necesidad y universalidad para constituir o fundamentar la experiencia misma, y, así, el conocimiento de las cosas. Por ello, hay que decir que no ocurre de manera contraria, que la experiencia preceda en cuanto tal a nuestras condiciones de posibilidad a priori, pues ello sería simplemente imposible.

\section{L A APERCEPC I Ó N TRASCENDENTAL Y LAS IDEAS INCONDICIONADAS}

Es necesario continuar con la precisión de estos límites relativos al conocimiento científico, pues la manera cómo operan nos sirven para criticar toda pretensión de conocimientos imposibles de alcanzar para

4 Sabemos que la experiencia según Kant será la base del conocimiento científico el cual comprenderá los juicios sintéticos a priori. Estos juicios, que no desarrollo aquí, presuponen el tema central de la metafísica trascendental que Kant pretende fundamentar: a saber, si es posible o no establecer conocimientos necesarios acerca del mundo y, consecuentemente, un fundamento firme para las ciencias. No obstante, cabe decir que este conocimiento científico al encontrar sus bases en algo a priori es patente que no dejará de presuponer una necesidad y universalidad que no pretenderá venir sino del entendimiento humano y no de las cosas. Y todo esto con el propósito de evitar un uso dogmático de la razón, así como evitar la caída en el escepticismo (Kant, 2007, p. 56) 
la razón. Por supuesto, también en esta crítica reconoceremos la imposibilidad de una comprobación de la existencia de un ser divino, pero considero que analizar los límites de todo conocimiento del mundo contribuye mejor a la comprensión de esto mismo en un desarrollo posterior.

Señala Kant que toda noción de necesidad guarda su fundamento en una condición trascendental, y que, por tanto, debe haber un fundamento trascendental para la unidad de la conciencia cuando realiza la síntesis de lo diverso, la cual se contiene en nuestras intuiciones $y$, así, de todos los objetos de nuestra experiencia. En otras palabras, debe haber un fundamento precisamente para esta unidad de las distintas percepciones a partir de nuestra conciencia. Nos dice Kant que esta "condición originaria y trascendental no es otra que la apercepción trascendental" (Kant, 2007, p. 136). Pero no se trata de una apercepción empírica, es decir, una percepción interna siempre mudable, una sin establecerse un yo fijo de la cual somos conscientes todo el tiempo, sino más bien la percepción acerca de una identidad constante, no mudable ni transitoria, más allá de un tiempo determinado. Nos dice Kant:

Lo que necesariamente tiene que ser representado como numéricamente idéntico no puede ser pensado como tal a través de los datos empíricos. Anteriormente a toda experiencia, ha de haber una condición que haga posible esa misma experiencia y que dé validez a tal suposición trascendental. (Kant, 2007, p. 136)

UUna representación de la identidad de mi yo, que prescinde de datos empíricos o de un fluir mudable, un yo que sea la condición de posibilidad de toda experiencia humana es precisamente en lo que consiste la apercepción trascendental.

La unidad de conciencia y síntesis de lo diverso, una función que realiza nuestro psiquismo cuando unifica toda diversidad de intuiciones mediante una representación, ha de ser una unidad a priori, ya que en caso contrario nuestro conocimiento carecería de objetos (Kant, 2007, p. 138). Es decir, es necesario asumir nuestra unidad de conciencia como la sintetizadora de toda la diversidad de nuestras intuiciones, de modo que podamos siquiera referirnos a objetos en cuanto tales. Así, la realidad objetiva de nuestro conocimiento empírico, por tanto, sólo es posible gracias a la referencia a un objeto en cuanto trascendental. Por ello, Kant señala: "(...) la realidad objetiva de nuestro conocimiento se basará en la ley según la cual, en la experiencia, esos fenómenos han de estar sometidos a las condiciones de indispensable unidad de apercepción (...)" (Kant, 2007, p. 110). Nuestra conciencia por medio de esta regla a priori de la apercepción trascendental somete a la unidad a todo fenómeno (Kant, 2007, p. 139), ya que no sería posible articular la variedad de fenómenos por medio de una percepción sin esta condición de posibilidad a priori ${ }^{5}$. Por eso agrega Kant:

El entendimiento no es, pues, una mera facultad destinada a establecer leyes confrontando fenómenos, sino que él mismo es la legislación de la naturaleza. Es decir, sin él no habría naturaleza alguna, esto es, unidad sintética y regulada de lo diverso de los fenómenos. (...)

5 Incluso desde aquí Kant ya enuncia que la ligazón de todos los fenómenos según leyes necesarias es algo que se halla sólo en una afinidad trascendental, pues lo que consideramos una afinidad empírica en los objetos será producto de la primera (Kant, 2007, p. 140). 
La unidad de apercepción es, pues, el fundamento trascendental que explica la necesaria regularidad de todos los fenómenos contenidos en una experiencia. (Kant, 2007, p. 149)

Nuestro entendimiento es la facultad que construye las leyes de la naturaleza por medio de la experiencia de los fenómenos, pero principalmente en virtud de su propia legislación. Es decir, toda unidad sintética que consideramos en la naturaleza o regulación por medio de alguna ley proviene en última instancia de nuestra apercepción trascendental debido a que el fundamento de dicha regulación hasta donde podemos comprender es justamente trascendental. Es decir, no sería posible reconocer naturaleza alguna sin esta unidad sintética que no proviene sino de nuestro entendimiento.

La unidad de apercepción es, pues, la condición de posibilidad de toda representación. Por este motivo, para Kant, es necesario decir que "el Yo pienso tiene que poder acompañar a todas mis representaciones" (Kant, 2007, p. 153), ya que no sería posible representar algo concreto. Esta unidad sintética de lo diverso de todo tipo de intuición constituye, entonces, el fundamento de la identidad de la apercepción, la cual es pues anterior a todo pensamiento sobre alguna representación. Por esta razón, concluye Kant: "Este principio, el de la apercepción, es el más elevado de todo el conocimiento humano" (Kant, 2007, p. 155). Por ello nos dice Torreti: "Al mostrar así que ella es la condición de posibilidad de la síntesis que funda toda intuición pura y empírica, Kant hace de la apercepción el principio primero del conocimiento" (Torreti, 1980, p. 295). En otras palabras, sin la apercepción trascendental no sería posible el conocimiento en general.

Ahora bien, hay que añadir los análisis que establece Kant acerca del entendimiento y la razón. El motivo de esto reside en que según Kant el entendimiento no es capaz por sí solo de suministrar conocimientos sintéticos a partir de los conceptos que aprehende de la sensibilidad ${ }^{6}$. Es decir, los conocimientos sintéticos que denominamos principios no pueden provenir del entendimiento en última razón; sin embargo, llamamos a todas nuestras proposiciones universales principios en razón de una comparación. Señala Kant: "Si el entendimiento es la facultad de la unidad de los fenómenos mediante reglas, la razón es la facultad de la unidad de las reglas del entendimiento bajo principios" (Kant, 2007, p. 302). Y es que el entendimiento se distinguirá de la razón para Kant, ya que si bien el entendimiento se refiere a objetos que le suministra la sensibilidad la razón en cambio nunca se referirá directamente a la experiencia o a algún objeto sino al entendimiento con la finalidad de dar unidad a priori a toda la diversidad de conocimientos que obtiene (Kant, 2007, p. 302). Esto nos lleva para Kant al uso puro de la razón, del cual nos explica:

La diversidad de las reglas y la unidad de los principios es, de hecho, una exigencia de la razón tendente a obtener una total concordancia del entendimiento consigo mismo, al igual que el entendimiento somete a conceptos la diversidad de la intuición consiguiendo así establecer una

6 Dice Kant por ello: "que todo lo que sucede tenga una causa no podemos inferirlo del concepto de lo que sucede. Al contrario, el principio indica que sólo de lo que sucede podemos obtener un concepto empírico determinado" (Kant, 2007, p. 302). Y es que los juicios sintéticos a priori y, por ejemplo, nuestro conocimiento de la causalidad no proviene sino de una exigencia y actividad del entendimiento. 
conexión dentro de tal diversidad. (Kant, 2007, pp. 304-305)

Comprender todas las reglas asumidas como una unidad de todos los principios en cuanto son una concordancia del entendimiento consigo mismo es una exigencia de la razón. Y es que, así como el entendimiento conforma la unidad de lo diverso de las intuiciones, así la razón conforma una unidad de la diversidad de conceptos del entendimiento.

Cabe discurrir, en todo caso, que Kant menciona la cuestión de si esta razón en su uso puro contiene principios sintéticos a priori, indicando que su respuesta es negativa. Sólo será posible para la razón actuar en la medida que nos formemos silogismos y juicios por medio del entendimiento. Podemos decir, entonces, que la razón actúa sobre el entendimiento, no sobre las intuiciones. Dice Kant: "La unidad de la razón no es, pues, la unidad de una experiencia posible, sino que es esencialmente diferente de ésta, que es una unidad del entendimiento" (Kant, 2007, p. 305). Así, la razón es usada para encontrar la condición general que posibilita todo juicio o silogismo; de hecho, el silogismo no es sino una subsunción de su condición bajo una regla general (Kant, 2007, p. 305).

Ahora bien, Kant sostiene que es posible encontrar un principio incondicionado del conocimiento condicionado por nuestro entendimiento, aquello que establezca unidad del entendimiento para poder llegar a su compleción (Kant, 2007. p. 306). Es decir, el fundamento del porqué nuestro entendimiento tiende hacia la unidad de la comprensión. Toda una serie de condiciones subordinadas supone ser incondicionada ella misma, aunque hayamos procedido de modo sintético porque lo condicionado sólo refiere a una condición tras otra y no hacia algo incondicionado de todas las condiciones. Pero podemos ver que lo incondicionado puede tener lugar en cuanto suministra materia para algunas proposiciones sintéticas a priori. Es decir, otorgar a las proposiciones sintéticas a priori una condición de posibilidad que las haga válidas objetivamente. Aunque cabe señalar que el uso que se pueda hacer de este tipo de principio incondicionado jamás podrá tener un uso empírico adecuado (Kant, 2007, p. 306). Por lo tanto, hay que señalar también que su uso será inmanente y no trascendente. De esta manera, hay que decir que en principio no podemos predicar algo con necesidad o universalidad empíricamente desde fuera, sino sólo desde nuestro entendimiento. Por este motivo, señala Kant que es necesario examinar si hay consecuencias que se siguen de este tipo de principio incondicionado que posean validez objetiva o no (Kant, 2007, pp. 306-307).

Tenemos claro que, según Kant, la función de la razón en cuanto realiza inferencias consiste en la universalidad de un conocimiento conceptual, ya que un silogismo es precisamente un juicio que se encuentra determinado a priori en toda la extensión de su condición (Kant, 2007, p. 315). La síntesis de nuestras intuiciones en cuanto una totalidad es llamada una universalidad; por tanto, el concepto trascendental de razón no sería sino el de la totalidad de las condiciones en la medida que la tomamos como una totalidad incondicionada. De ahí que, siendo sólo lo incondicionado lo que hace posible a la totalidad de las condiciones y la totalidad de las condiciones algo incondicionado, podemos demostrar que el concepto puro de la razón consiste 
fundamentalmente en el concepto de lo incondicionado (Kant, 2007, p. 315). Y es que de otra manera no tendríamos cómo admitir algún conocimiento universal si no asumimos una totalidad incondicionada de toda condición. Esta totalidad incondicionada proviene de nuestra razón, la cual buscará dar validez objetiva a nuestros juicios y proposiciones sintéticas en general.

Así, Kant considera que estos conceptos puros de la razón son necesarios al menos como proyectos tendentes para proseguir con la unidad del entendimiento a partir de una totalidad en la síntesis de las condiciones; además, estos conceptos se encuentran en la naturaleza de la razón humana (Kant, 2007, p. 316). Luego, Kant procede a llamar a estos conceptos puros de la razón ideas trascendentales, pues son los conceptos necesarios de la razón a los que llegamos prescindiendo de los sentidos al carecer de un objeto correspondiente; además, estas ideas trascendentales $O$ conceptos puros contemplan todo conocimiento empírico como determinado por una totalidad absoluta de condiciones (Kant, 2007, p. 318). De otra manera, no sería posible asumir ningún conocimiento de las cosas u objetos, ya que no pertenecerían a ningún principio que las pudiera ordenar en una unidad de lo diverso o totalidad incondicionada.

Kant señala que estas ideas trascendentales se reducen a tres: la primera alberga la unidad absoluta incondicionada del sujeto pensando, la segunda la unidad absoluta de la serie de condiciones del fenómeno, y la tercera la unidad absoluta de la condición de todos los objetos del pensamiento en general. A esta primera unidad le corresponde la idea de alma, a la segunda, la idea de mundo $y$, finalmente, a la tercera le corresponde la idea de Dios; aunque, cabe decir que la razón pura no se refiere a estas ideas como objetos sino sólo como conceptos (Kant, 2007, p. 323). Sin embargo, Kant señala que su demostración como ideas es una exigencia de la razón:

De estas ideas trascendentales no podemos realizar una deducción objetiva en sentido propio, al modo como la hicimos de las categorías, ya que, precisamente por ser simples ideas, no hacen en realidad referencia a un objeto que pueda dárseles como correspondiente. Pero sí podríamos efectuar una derivación subjetiva de las mismas partiendo de la naturaleza de nuestra razón. (Kant, 2007, p. 324)

Estas ideas no pueden ser demostradas objetivamente, pues ninguna de ellas refiere a un objeto de la experiencia, ni tampoco se relaciona en la interacción de nuestro entendimiento con la misma. Sin embargo, sí es posible demostrarlas subjetivamente, al punto que incluso son producto de una exigencia de nuestra razón.

Y es que, si no asumimos un sujeto cognoscente a modo de una unidad incondicionada no sería posible pensar para este sujeto. Si no asumimos un mundo bajo condiciones que puedan ser representadas por nuestros fenómenos no sería posible pensar ningún mundo condicionado. Y también, si no asumimos un Dios que piense a todos los objetos del mundo en cuanto condicionados, a modo general, no sería posible asumir ningún pensamiento acerca de condiciones de posibilidad de realidades objetivas. Ahora, es importante decir que para Kant estas ideas trascendentales carecen de objeto, ya que si establecemos silogismos acerca de ellas no se encontrarán basadas 
en premisas empíricas a partir de las cuales podamos decir algo que en efecto nos sea conocido. Más bien, Kant se muestra bastante reacio a aceptar dicha labor, al punto que incluso señala que si lo intentáramos caeríamos en ilusiones o sofismas, puesto que sólo obtendríamos ficciones y productos fortuitos (Kant, 2007, pp. 326-327). Siendo el tema de Dios el que más nos interesa respecto del presente trabajo, cabe mencionar que Kant mismo reitera que sólo podemos pensarlo a modo de concepto trascendental como un ser de todos los seres que posea una incondicionada necesidad (Kant, 2007, p. 327). Y es que es conocida la sección de la dialéctica trascendental donde Kant señala que precisamente por estos motivos, en un amplio desarrollo, se concluye que es imposible probar la existencia de Dios. Básicamente, sabemos que Kant niega cualquier intento de probar la existencia de un ser supremo, porque niega los argumentos físico-teológicos, cosmológicos y ontológicos, aunque diga que éste último tipo resume los anteriores.

Como sabemos, el argumento ontológico es rechazado por Kant debido a que no es contradictorio pensar en la no existencia de un Dios. Dios y su existencia no se identifican necesariamente, ya que la existencia sería un predicado que se añade al concepto de Dios. Es decir, no es parte de nuestra idea de perfección divina el que posea necesariamente la existencia. De ahí que, por ejemplo, para Kant decir 'Dios no es perfecto' sería contradictorio, pero decir 'Dios no existe' no tendría que serlo en absoluto. Sería contradictorio decir que un triángulo existe y no posee tres lados; sin embargo, no es contradictorio suprimir dicho triángulo y sus lados a la vez (Kant, 2007, p. 501). A su vez, podemos decir que Kant rechaza estos argumentos dado que no podemos asumir la existencia de un ser necesario absolutamente sino sólo desde nuestra concepción de necesidad absoluta. Necesidad la cual sólo refiere a algo teórico, pero no por ello derivaremos de la necesidad lógica una necesidad empírica de la cual yo pueda, en efecto, inferir una primera causa del cosmos (Kant, 2007, p. 526). Por este motivo para Kant toda tentativa de la razón por probar la existencia de Dios es estéril ya que "el conocer un ser supremo requiere hacer de ellos [los principios sintéticos del entendimiento] un uso trascendente para el que nuestro entendimiento no está equipado" (Kant, 2007, p. 527). Esto porque sabemos que nuestro entendimiento partiendo de nuestra razón otorga universalidad y necesidad a nuestros conocimientos, pero no podemos saber que fuera al revés, a saber, que a partir de una universalidad de nuestros conocimientos necesarios podamos inferir un principio de todas las cosas a modo de una primera causa. Sólo podemos inferir a Dios como una exigencia de la razón a partir de nuestra subjetividad, pero no de un mundo que sea objetivo a ciencia cierta del cual yo derive la existencia de este ser supremo de todas las cosas. Por tanto, quedan concluidas las pretensiones de comprobación alguna de un ser divino a partir de la razón humana; i. e. que no puede comprobarse la existencia de Dios, es decir, no puede probarse a Dios sintéticamente.

Por supuesto, según Kant tampoco podría ser probada la negación de este ser divino ya que representa un ideal perfecto en cuanto concluye y corona el conocimiento humano entero (Kant, 2007, p. 530). Sin embargo, la importancia de reconocer ideas trascendentales nos hace patente que, si bien no podemos probar su realidad objetiva, ya que esto podría significar caer en ilusiones, no podemos prescindir de ellas en cuanto 
postulados que la razón produce. Por ello, dice Corazón: "Este conocimiento hace que seamos conscientes de ambas cosas: de que es inevitable y de que no es más que una ilusión. (...) Da razón del deseo continuo de hacer metafísica y nos advierte al mismo tiempo de su imposibilidad" (Corazón, 2004, p. 137). Es inevitable para nosotros desarrollar una metafísica especulativa, pero debemos ser conscientes de que al instanciar realidades objetivas acerca de estas ideas trascendentales sería posible caer en una ilusión. Por tanto, es imprescindible reconocer esta imposibilidad humana.

En suma, todo conocimiento al que nuestro entendimiento puede acceder se ve estimulado por una necesidad lógica que transpone al mundo, al modo de una necesidad empírica. Por esta razón algunos filósofos creyeron que podían probar la existencia de Dios; no obstante, ello es imposible científicamente Ahora, hay que decir que atendiendo a la idea trascendental de mundo nosotros formamos conceptos sobre la naturaleza a partir de lo que nos exige la razón. Sin embargo, si bien Kant no duda de la existencia de un mundo externo a nuestra sensibilidad, menciona que este mundo sólo será cognoscible a modo de fenómeno, y, por tanto, según los esquemas de nuestra racionalidad. Ahora bien, independientemente de este esquema racional que nosotros le imponemos a la exterioridad no es posible desarrollar conocimiento científico alguno ${ }^{7}$. Por lo tanto, nuevamente nos encontramos con una crítica acerca de los límites de nuestro saber científico y no sólo de alguna metafísica especulativa en tanto dogmática.

\section{Hacia una racionalización del concepto de religión}

En esta última parte me propongo explicar la tesis de que la filosofía crítica de Kant gestó las condiciones que estimularon el desarrollo de un concepto de religión racional. Cabe decir que este desarrollo es importante pues considero que sirve de presupuesto para todo desarrollo posterior de alguna filosofía de la religión. Al abandonar la teología natural aparentemente el ámbito de lo religioso debería ser descartado. Lejos de eso, Kant considera que la religión en cuanto no revelada puede conciliarse con conceptos racionales, y, en cuanto la idea de Dios nos sirve de ideal regulativo, es necesario admitir un determinado tipo de fe.

Sabido es que Kant enseña que las ideas trascendentales son ideas reguladoras de todo nuestro conocimiento. Kant interpreta que nuestras ideas brindan unidad a todos nuestros conceptos determinando a priori sus relaciones; entonces, cualquier idea trascendental brinda a nuestro entendimiento una unidad completa gracias a la cual nuestros conocimientos adquieren una ligazón por leyes necesarias (Kant, 2007, p. 532). Por ende, este uso regulativo de la razón consiste en la unificación de todos nuestros conocimientos particulares según la atribución de una universalidad; de manera que se conforma un uso hipotético de la razón en cuanto existe una tendencia a la unidad sistemática de nuestro conocimiento según algún criterio de verdad de reglas, pero reconociendo que esta unidad sistemática es sólo proyectada (Kant, 2007, p. 533). Por tanto, la razón atribuye un uso lógico al

7 Cabe recordar que, para Kant, las condiciones de posibilidad a priori no pueden provenir de los objetos ya que en dicho caso las condiciones ya no serían necesarias sino contingentes. Las condiciones de posibilidad a priori en cuanto necesarias y universales sólo pueden provenir, por tanto, de la razón y no de fuentes empíricas.

Vol $18 N^{\circ} 2$ Jul. - Dic. 2019 
entendimiento por medio de sus ideas con el fin de ayudarlo en el conocimiento de las cosas; así, la razón posee su principio trascendental (Kant, 2007, p. 534).

El uso de la razón es, entonces, estrictamente hipotético ${ }^{8}$. Las ideas

trascendentales las admitiremos, ya que las necesitamos para unificar todo nuestro conocimiento; esto es, que sin las ideas de Dios, alma y mundo no sería posible el conocimiento, pues no estaríamos asumiendo algún esquema de principio regulador y unificador sistemático del conocimiento de toda la naturaleza (Kant, 2007, p. 549). Aceptaremos estas ideas trascendentales por motivos especulativos, aunque no porque consideremos que alcanzamos algún conocimiento objetivo de éstas ${ }^{9}$. De este modo, Dios será considerado como concepto necesario para explicar la posibilidad de las realidades objetivas como verdaderas en nuestros conocimientos. Por eso Kant en sus Lecciones sobre la filosofía de la religión señala incluso que el concepto de Dios es necesario, pues postularlo es la única manera de tener la esperanza de que el mundo y la naturaleza encierren un sentido determinado:

(...) nuestro entendimiento no puede conocer las cosas más que por notas universales; pero eso es una limitación del entendimiento humano, y no puede tener lugar en Dios. Por consiguiente, pensamos al máximo del entendimiento, esto es, entendimiento intuitivo. Aquí no tenemos ningún concepto; pero este máximo nos sirve para hacer determinados los grados menores; pues el máximo es determinado. (Kant, 2000, p. 68)

Nuestra inteligencia sólo puede aproximarse al conocimiento del mundo mediante proposiciones universales. Sin embargo, ello no tiene lugar en Dios, ya que no lo necesitaría por ser Él quien conoce las cosas como son en sí mismas, a diferencia del hombre. La inteligencia suprema de Dios es meramente intuitiva, y es en virtud de alguna intuición máxima de concepto suya que nosotros participamos en la medida de lo posible de su conocimiento mediante nuestras determinaciones y medidas.

Ahora bien, cabe recordar que Kant, por supuesto, nos advierte que no debemos asumir esta idea de Dios más allá del de idea reguladora, pues creer que podemos probar su realidad objetiva no sería sino terminar no sólo creyendo en Dios de manera dogmática y acrítica, sino también muy peligroso. Lamentablemente quien lo intente antropomorfizará a Dios, y podrá, consecuentemente, terminar imponiendo fines a la naturaleza de acuerdo con sus conveniencias y según creencias particulares de manera violenta y dictatorial (Kant, 2007, p. 560). Por ello, será necesario prevenir toda forma de teología acrítica y más bien fundar alguna teología racional que prescinda de estos contenidos dogmáticos especulativos.

Como sabemos, según Kant la razón humana posee una vertiente que es práctica, la cual es tan esencial como su vertiente teórica. Es decir, es una

8 Cabe señalar que Kant señala que a falta de esta regulación la razón no podría nunca pensar un uso coherente del entendimiento ni, por tanto, criterio alguno para creer hallar alguna verdad empírica ni validez objetiva (Kant, 2007, p. 536). )

9 El caso de la idea de Dios sirve en cuanto regulador de la suposición que tenemos de que él sea la causa única y omnisuficiente de todas las series cosmológicas (Kant, 2007, p. 556), como si todas las cosas procedieran de un ser omnicomprensivo que dispuso todas las conexiones del mundo según principios de unidad sistemática a modo de una causa suprema con un propósito de razón suprema (Kant, 2007, p. 557). 
exigencia racional el querer establecer proposiciones de contenido moral. En la Crítica mencionada Kant dice que las preguntas que nos podemos formular a partir de todo lo analizado, conforme a las cuales se deriva la necesidad de todos los postulados centrales del canon de la razón pura son: 1) ¿Qué puedo saber? 2) ¿Qué debo hacer?, y 3) ¿Qué puedo esperar? Siendo la primera meramente especulativa, la segunda meramente práctica, y la tercera es al mismo tiempo práctica y teórica (Kant, 2007, p. 630). En cuanto a la primera Kant confía en haber agotado todas las posibles respuestas según la Crítica. La segunda pregunta será necesario tratarla por la moral. La tercera pregunta refiere hacia el esperar obtener la felicidad debido a ser merecedor de ella por la moral, así como se espera obtener el saber debido a buscar el conocimiento de las cosas (Kant, 2007, p. 630); por este motivo, es tanto teórica como práctica. Dice Kant que en cuanto idea trascendental también doy al mundo leyes éticas gracias al postulado de la libertad de seres racionales y postulo leyes necesarias de la moralidad, y a esto llamamos mundo moral; la idea de un mundo moral poseedor pues de realidad objetiva (Kant, 2007, p. 632). En la Fundamentación para una metafísica de las costumbres Kant señala:

Cada cosa de la naturaleza opera con arreglo a leyes. Sólo un ser racional posee la capacidad de obrar según la representación de las leyes o con arreglo a principios del obrar, esto es, posee voluntad. Como para derivar las acciones a partir de leyes se requiere una razón, la voluntad no es otra cosa que razón práctica. (Kant, 2002, p. 91)

Los hombres por ser racionales conocemos las cosas en virtud de leyes que traducimos a la naturaleza. Así, en el ámbito de la moral necesitamos también estas leyes y principios para regir nuestra voluntad. Ésta consiste precisamente en nuestra capacidad racional para discernir nuestras acciones. Por ello, Kant llama a la voluntad en última instancia 'razón práctica'.

Las representaciones acerca de principios objetivos para la voluntad en nuestro terreno moral son llamados por Kant imperativos, y es que todo imperativo será un deber-ser en cuanto una ley objetiva de la razón para nuestra voluntad (Kant, 2002, p. 92). Como sabemos, el razonamiento kantiano del deber moral es consecuente con su metafísica trascendental, a saber, el desarrollo de imperativos que no se estipulen a partir de lo empírico sino de lo necesario y universal de la razón (Kant, 2002, p. 101). Concluye Kant: "Por lo tanto, tendremos que indagar enteramente a priori la posibilidad de un imperativo categórico, al no contar aquí con la ventaja de que su realidad esté dada en la experiencia, con lo cual su posibilidad sólo sería necesaria para explicarlo y no para estipularlo" (Kant, 2002, p. 102). Es decir, los imperativos categóricos serán desarrollados por la razón independientemente de la influencia de la experiencia para poder servirnos de ellos a modo de prescripciones morales que puedan ser explicadas universalmente. Así, conocida la máxima del imperativo categórico podemos reafirmar la importancia de la razón al establecer los contenidos universales de todo enunciado. Así, sabemos que para Kant nace la búsqueda por una moral de la autonomía. Una moral que no recurra a fuentes a posteriori, o de manera heterónoma, sino que busque sus principios o leyes a partir de la exigencia de la propia razón. Esto 
será, pues, una moral autónoma basada en fuentes a priori.

De este modo, para Kant este mundo moral o leyes de la moralidad que consideramos necesarias y universales prescriben que obremos conforme al deber. Sin embargo, al haber enseñado que el recto obrar por el deber es el fundamento o condición de posibilidad a priori de la moral para un actuar conforme a una ley universal, Kant es consciente que la búsqueda de la felicidad no es prioridad para determinar lo que es verdaderamente moral. La legislación de la razón por una moral conforme a una ley universal es el único criterio formal del que disponemos para desarrollar una ética. Por lo que dirá Kant que respecto de la felicidad sólo debemos actuar mediante lo cual vamos a hacernos dignos de ser felices (Kant, 2007, p. 632), y no para ser felices necesariamente. Así, señala Kant que, si tomamos como base una razón suprema en este terreno ético, al igual que una razón del mundo, asumiremos que se nos dictará normas de acuerdo con leyes morales conforme a las causas de la naturaleza; y es que según Kant esta idea de una razón o inteligencia suprema debe ligar a la moral perfecta con la dicha suprema, esto es, unir el ideal del bien supremo con la felicidad (Kant, 2007, p. 633). Dice Kant:

De esta manera, a través del concepto de sumo bien como objeto y fin final de la razón pura práctica, la ley moral conduce hacia la religión, esto es, al conocimiento de todos los deberes como mandatos divinos, no como sanciones $u$ ordenanzas arbitrarias y por sí mismas contingentes de una voluntad extraña, sino comoleyes esenciales de cualquier voluntad libre por sí misma, las cuales han de ser consideradas pese a todo como mandatos del ser supremo, pues nosotros no podemos esperar conseguir el sumo bien, cuyo auspicio constituye un objeto de nuestro afán convertido en deber por la ley moral, sino a partir de una voluntad moralmente perfecta (santa y bondadosa) al tiempo que omnipotente y, por lo tanto, mediante la concordancia con esa voluntad. (Kant, 2011, p. 247)

Es decir, al no poder fundamentar la moral sino gracias a un bien supremo es necesario que la moral nos conduzca hacia la religión, pues este bien supremo tiene que ser Dios. Así, debemos aspirar a obedecer a los deberes ya no sólo por ser racionales sino por pertenecer a la libertad y mandato supremo de un Dios. Sólo su voluntad moralmente perfecta y omnipotente puede otorgarnos la aspiración de que podamos alcanzar dicho sumo bien mediante nuestra moral racional. En caso contrario, pues, la moral carecería de fundamento último, ya que no podríamos estar seguros de que exista un fundamento de la moral en sí misma

Así, para Kant, la religión es necesaria en tanto que es ella la que postula este sumo bien, el cual le da sentido y fundamento a la moral. Kant no es reacio a la concepción de la religión como tal o en sí misma, sino que sólo rechazará el que los mandatos morales se asuman como divinos o institucionalmente religiosos cuando en realidad provengan de una voluntad arbitraria de los hombres. Entonces, no debe perderse de vista el que sea necesario postular para Kant un fundamento para la moralidad del ser humano, lo cual no hace sino que Kant siga, en cierto modo, la opinión o juicio de un grupo de filósofos anteriores a él. Conviene señalar junto con Belaúnde:. 
Por último, venciendo el agnosticismo, ínsito en el sistema de Kant, el deber imperativo y universal postula lo absoluto, del mismo modo que el bien platónico, el amor y la justicia de Agustín y la idea de lo perfecto de Descartes postulaban la existencia de una fuente perenne de bien, justicia, ideal y amor (Belaúnde, 1993, p. 64).

$Y$ es que es innegable que Kant se parece más en este punto al conjunto de pensadores que consideran que sin el postulado de un bien supremo, a pesar de que podamos ejercitar la moral por medio de proposiciones, no tendría ningún sentido creer que en verdad nuestras acciones puedan llegar a ser consideradas realmente buenas. En otras palabras, no es posible probar la existencia de este bien supremo, pero si no se le supone sería imposible creer que podamos llegar a obrar el bien.

Por todo ello, es necesario discurrir acerca de nuestros mandatos morales desde la razón en la medida que nos sea posible apuntar hacia un sumo bien real. Señala Allison: "As usual, the operative assumption is that since we are morally required to do all in our power to realice the Highest Good, it must be assumed to be possible of attainment" (Allison, 2003, p. 172). Sólo mediante el ideal del bien supremo podemos ligar a la moral con algo derivado de un mundo inteligible para regular nuestra conducta en este mundo sensible. Así, "Dios y la vida futura constituyen dos supuestos que, según los principios de la razón pura, son inseparables de la obligatoriedad que esa misma razón nos impone" (Kant, 2007, p. 634).

De esta manera, el sumo bien al que aspiramos por medio de nuestra razón implicará la existencia de Dios, así como de la inmortalidad del alma, ya que son consecuencias necesarias para el fundamento de la ley moral. Además, sólo esta idea de bien supremo podría hacer posible toda unidad teleológica (Kant, 2007, p. 634). De hecho, en el prólogo a su primera edición de La Religión dentro de los límites de la mera Razón, Kant señala que:

Pues sin ninguna relación de fin no puede tener lugar en el hombre ninguna determinación de la voluntad, ya que tal determinación no puede darse sin algún efecto, cuya representación tiene que poder ser admitida, si no como fundamento de determinación del albedrío y como fin que precede en la mira, sí como consecuencia de la determinación del albedrío por la ley en orden a un fin (finis in consequentiam veniens), sin el cual un albedrío que no añade en el pensamiento a la acción en proyecto algún objeto determinado objetiva o subjetivamente (objeto que él tiene o debiera tener), un albedrío que sabe cómo pero no hacia dónde tiene que obrar, no puede bastarse. (Kant, 2001, pp. 22-23)

La voluntad del hombre sólo puede determinarse mediante algún fin, debido a que es necesario buscar un efecto consiguiente. Y es que, si bien este fin no representa el fundamento de la determinación de nuestras acciones morales, sí se observa que ese fin es una consecuencia necesaria y fundamento de la moral. La ley sólo tiene orden en virtud de un fin, ya que sin éste el albedrío no busca ningún proyecto para su recto obrar.

No es posible que a la razón humana le sea indiferente la consecución de un fin. 
Este es precisamente la felicidad, el cual no es sino lo concordante respecto de la observancia y cumplimiento del deber (Kant, 2001, p. 23). Pero para esto tenemos que asumir la idea de un bien supremo en el mundo, por lo que aceptamos la posibilidad de un ser supremo, moral, omnipotente y santísimo (Kant, 2001, p. 23). Así, señala Kant:

No puede, pues, ser indiferente a la Moral el que ella se forme o no el concepto de un fin último de todas las cosas (bien entendido que el concordar en ese fin no aumenta el número de los deberes, pero les proporciona un particular punto de referencia de la unión de todos los fines); pues sólo así puede darse realidad objetiva práctica a la ligazón de la finalidad por libertad con la finalidad de la naturaleza, ligazón de la que no podemos prescindir. (Kant, 2001, pp. 23-24)

Para poder hablar de moral es necesario hacernos el concepto de un fin último de todas las cosas, incluido del hombre mismo. Sólo mediante este bien sumo, fin último de todas las cosas, es que podemos tener un punto de referencia objetivo para hablar de moral. Esto porque sin este fin último la moral carecería de realidad objetiva y sería un mero discurso subjetivo inacabable. Consiguientemente, no puede disociarse la finalidad de nuestra libertad con una finalidad de la naturaleza, ya que si la moral carece de dicha finalidad nuestro conocimiento no tendría cómo no carecer de ciencia.

Ahora bien, hay que decir que Kant admite que la creencia en Dios es parte de creencias doctrinales, en tanto no nos podemos olvidar de que nada de lo que disponemos nos lleva a presuponer que la idea de Dios tenga efectivamente una existencia real. Así, estamos obligados a servirnos de nuestra razón como si todo fuese mera naturaleza, así como de una unidad teleológica que constituye una condición tan grande de la aplicación de la razón a la naturaleza que no podemos dejarla de lado (Kant, 2007, p. 643). Por este motivo, señala Kant: "La única condición que conozco que me presente tal unidad como guía en la investigación de la naturaleza consiste en la suposición de una inteligencia suprema que lo haya ordenado todo así de acuerdo con los fines más sabios" (Kant, 2007, p. 643). Agrega a esto Guyer:

The argument of Kant's teleology, as I suggested at the outset, is that the thought that the world is the product of intelligent design may be suggested to us or even forced upon us by our experience of organic nature, but that the only use we can make of this thought is for the regulative conception of the natural world as designed to be a fit arena within which we can reasonably strive to fulfill our moral vocation. (Guyer, 2007, p. 158)

Esta teleología es condición necesaria para Kant de todo discurso científico natural de modo que sea a su vez condición necesaria de un discurso moral con validez objetiva. Por tanto, es preciso postular un diseño inteligente que produzca la realidad de tal manera que sea cognoscible en medio de nuestra racionalidad, ya que en caso contrario no tendría fundamento alguno ningún conocimiento.

Por ello, para Kant, prescindiendo de Dios y una vida futura las normas de la moralidad pueden ser motivo de aplauso y admiración, pero no de propósito ni de práctica (Kant, 2007, p. 635) ${ }^{10}$. Además, dice Kant: "De ahí que la moral no suponga 
una teoría de cómo hacernos felices, sino de cómo debemos llegar a ser dignos de la felicidad" (Kant, 2011, p. 248). Así, si consideramos como un decreto divino llevar al mundo hacia su perfección moral, ésta debe condecirse con la voluntad de un ser supremo (Kant, 2001, p. 81). Debe, pues, darse un dominio de los principios buenos y no de los malos, liberarnos de la ley del pecado en virtud de vivir la justicia, ya que ella es lo que podemos alcanzar (Kant, 2001, p. 117). Dice Kant:

El dominio del principio bueno, en cuanto los hombres pueden contribuir a él, no es, pues, a lo que nosotros entendemos, alcanzable de otro modo que por la erección y extensión de una sociedad según leyes de virtud y por causa de ellas; una sociedad cuya conclusión en toda su amplitud se hace, mediante la Razón, tarea y deber para todo el género humano. (Kant, 2001, p. 118)

El principio bueno que Kant defiende a través de su moral debe recibir la contribución de los hombres por medio de la construcción de una sociedad con base en las virtudes más justas. Este es el deber que tiene toda sociedad y el género humano pues es a lo que podemos aspirar.

De esta manera, Kant mismo entiende que Dios puede ser soberano moral del mundo mediante la aspiración a esta sociedad justa. Sólo si pensamos un legislador supremo de una comunidad ética podemos aspirar a verdaderos deberes que serán representados como mandamientos suyos (Kant, 2001, pp. 124-125). Y, entonces, entenderemos nuestra comunidad ética donde el pueblo de Dios se identifica con nuestra sociedad y los mandamientos divinos con nuestras leyes de virtud (Kant, 2001, p. 125). Por tanto, sólo una fe religiosa pura puede fundar según Kant una iglesia universal, a modo de una fe racional en cuanto critique el valor moral de nuestras acciones rechazando obediencias pasivas y postulando una religión moral pura (Kant, 2001, pp. 128-129).

Así, es prudente señalar para nuestro propósito que Kant también advierte que es necesario examinar nuestras ideas éticas para alcanzar una purísima ley moral de la religión (Kant, 2007, p. 638). Esto porque las ideas morales han dado lugar a un concepto de ser divino que es más acertado en tanto se encuentra en perfecto acuerdo con los principios morales que se derivan de la razón y no por razones especulativas (Kant, 2007, p. 638). Dice Wood: "Theological morality also fails as an account of how we know what is obligatory, because its account is either circular or presupposes theoretical knowledge we cannot have" (Wood, 1999, p. 161). Pues, de esta manera, hemos de señalar que Kant es autor de una racionalización del concepto de religión producto de una racionalización de la moral:

(...) la legislación moral pura, por la cual la voluntad de Dios está originalmente escrita en nuestro corazón, no es sólo la condición ineludible de toda Religión verdadera en general, sino que es también lo que constituye propiamente ésta, y aquello en orden a lo cual la ley estatutaria puede contener solamente el medio de promoción y extensión de ello. Así pues, si la cuestión de cómo quiere Dios ser honrado debe ser respondida de modo universalmente válido para todo

10 Incluso Kant se muestra reacio a aceptar que la tesis de los sentimientos morales pudiera justificar a la moralidad, pues si suponemos una persona que fuera indiferente a estos sentimientos la moral no podría ser defendida con fundamentos sólidos (Kant, 2007, p. 645). 
hombre considerado meramente como hombre, no hay ninguna duda de que la legislación de su voluntad debe ser meramente moral; (...). (Kant, 2001, pp. 130-131)

La ley moral en cuanto racional es lo que nos brinda un concepto de religión verdadera. Es decir, es posible construir un concepto de religión nuevo amparado en nuestra racionalidad en la medida que aceptamos una ley moral que ha necesitado como postulado necesario y fin último a Dios. Para la legislación moral es necesario postular una legislación universal basada en condiciones de posibilidad a priori.

La religión por sí misma no tiene que ser causante de tergiversar a los individuos y hacerlos peores, como le preocupaba a Hume, a quien además consideramos el principal interlocutor de la Crítica de la razón pura de Kant. Para éste, la religión más bien puede ser portadora de máximas morales y contenidos los cuales pueden ser explicados y defendidos racionalmente. La religión verdadera se condice con nuestra ley moral interior, puesto que ésta es la condición de posibilidad a priori de una fe racional (Kant, 2001, p. 130). Sin embargo, esta fe racional al nutrirse de la ley moral concibe tener una racionalización a la que no podemos mostrar indiferencia. Señala Gómez:

Pero ya se ve que en la insólita conjunción de los dos términos «fe»y «racional», se busca a la vez una analogía y afinidad con las típicas convicciones de la tradición cristiana y una distancia. A destacar y caracterizar esta distancia dedicará Kant no pocas páginas de su libro sobre la religión. Pero, a pesar de la distancia, sigue siendo real la analogía y la afinidad. Hay algo religioso en esa actitud, aun cuando su objeto sea por lo pronto más bien la realidad del sujeto humano, a quien se otorga confianza en su «necesidad». (Gómez, 2005, p. 184)

La fe y la razón para Kant, si bien pueden ser distinguidas en la medida que no necesariamente lo doctrinario alberga una explicación racional, pueden en otros casos mostrar afinidad en el terreno de la moral. Así, Kant no quiere rechazar las enseñanzas religiosas como estrictamente dogmáticas en la medida en que podrían muchas de ellas contar con una explicación racional. Aunque, por supuesto, tendremos que marcar siempre una distancia respecto de las enseñanzas a las que no podamos acceder racionalmente. Es necesario partir del sujeto humano pues éste nos muestra que tenemos la necesidad de postular esta fe racional, con esta distancia y afinidad.

A tal punto llega la importancia que tiene Kant sobre la religión en cuanto racional, que podemos decir que busca sus condiciones de posibilidad desde la razón misma. Por ello, hay que decir que, para Kant, es posible construir un concepto de religión independiente de nuestras creencias particulares, es decir, sin recurrir necesariamente a la religión que hemos heredado por nuestras tradiciones. Nos dice Grondin: "En cuanto heredero de la Ilustración, Kant distingue la religión estatutaria, histórica y particular, de la religión universal que puede deducirse de la razón humana" (Grondin, 2010, p. 129). Por lo tanto, podemos decir que Kant ya está pensando en una conceptualización racional de la religión a causa del abandono de una teología dogmática especulativa. 
Por supuesto, Kant no apuesta por un abandono de las creencias religiosas particulares. Simplemente nos aporta que es posible pensar en un concepto de religión gracias a que es posible racionalizar también este concepto. Por este motivo no se sigue de su pensamiento una crítica de toda metafísica o forma de religión de manera despectiva, como pretendió sostener el pensamiento positivista. Kant sólo rechaza la metafísica dogmática especulativa en cuanto no reconoce sus propios límites, fundando así una metafísica trascendental. Y esto porque la filosofía tradicional se ocupó de problemas más allá de sus límites generando que los hombres se vean enfrascados en disputas inacabables por exceder estas limitaciones. Además, no hay que perder de vista que la crítica de todo dogmatismo religioso se puede aplicar de la misma manera a todo discurso científico que peque con la misma cerrazón. A saber, una crítica que vaya contra la pretensión de que tenemos razones para suponer que exista una necesidad empírica, la cual pueda ser traducida sin tener en cuenta el rol activo de las condiciones de posibilidad de todo nuestro conocimiento.

La religión deberá ser considerada también como parte de nuestros conocimientos en general. La exigencia de la razón produce que busquemos hacer ciencia, formular principios morales, y confiar en que todo ello se sostiene bajo el designio inteligente y sumamente bueno de un Dios. Sin embargo, al tener el problema de que hemos instanciado esta idea de Dios por medio de contenidos empíricos los cuales nos distraen de su uso regulador y racional, es prudente también racionalizar la religión. Por eso, en palabras de Gómez: "Kant busca, sin dejar la exigencia de autonomía, una «teonomía» no heterónoma, que dé firmeza a lo absoluto del deber" (Gómez, 2005, p. 196). Y es que podemos encontrar una racionalidad inmersa en la religión la cual debe ser examinada para manifestar esta idea de Dios o de ideal supremo en la medida de lo posible para nuestra razón.

Es conveniente citar aquí la siguiente percepción de Kant: "Por muy toscos que fueran los conceptos de religión introducidos por los antiguos usos que todavía quedaban del estado de barbarie de los pueblos, ello no impidió que la parte más ilustrada se dedicara libremente a investigar sobre tal objeto" (Kant, 2007, p. 659). La religión estatutaria o histórica, la cual heredamos y algunos aceptan de manera incuestionada nos ha heredado también la posibilidad de su investigación a partir de nuestra razón. Sánchez, quien a pesar de no mostrarse tan optimista en torno a esta concepción de religión racional en cuanto pudiera implicar algún tipo de rechazo de nuestras creencias particulares reconoce:

El producto final del gigantesco esfuerzo ilustrado tendría una duración efímera. Pero algo quedaba ya para el futuro: la religión había pasado a ser objeto del pensamiento de manera autónoma respecto de los enfoques teológicos que habían sido hegemónicos hasta aquel momento. La religión quedaba así preparada para llegar a ser objeto de ciencia y reflexión. (Sánchez, 2003, p. 149)

La ilustración tiene un mérito innegable y un gran aporte para el estudio de la religión. El abandonar por un momento la teología especulativa y dogmática, las cuales habían ejercido efectivamente una hegemonía muchas veces despótica, no hizo sino el que naciera un concepto de 
religión que podrá ser objeto de estudio y permitirá posteriores comparaciones.

Será razonable, pues, que se investigue a la religión como objeto. Indiscutiblemente, es gracias a este aporte que podemos pensar hoy también a las religiones y encontrar una racionalidad subyacente que nos permita estudiarlas en conjunto.

\section{REFERENCIAS BIBLIOGRÁFICAS}

Allison, H. (2003) Kant's theory of freedom, Cambridge University Press.

Belaúnde, V. A. (1993) Obras completas VI, La Síntesis Viviente, Palabras de Fe, Pontificia Universidad Católica del Perú - Instituto Riva-Agüero, Lima.

Dufrenne, M. (2010) La noción de «a priori», Ediciones Sígueme, Salamanca.

Gómez, J. (2005) "La filosofía de la religión de I. Kant" en Filosofía de la Religión. Estudios y textos, Edición de Manuel Fraijó, Editorial Trotta, Madrid.

Grondin, J. (2010) La filosofía de la religión, Traducción de Antoni Martínez Riu, Editorial Herder, Barcelona.

Guyer, P. (2007) "Beauty, Freedom, and Morality: Kant's Lectures on Anthropology and the Development of His Aesthetic Theory" en Essays on Kant's Anthropology, Edited by Brian Jacobs and Patrick Kain, Cambridge University Press.

Kant, I. (2011) Crítica de la razón práctica, Edición de Roberto $\mathrm{R}$. Aramayo, Alianza Editorial, Madrid.

Kant, I. (2007) Crítica de la Razón Pura, Prólogo, traducción, notas e índices de Pedro Ribas, Editorial Taurus, México.

Kant, I. (2002) Fundamentación para una metafísica de las costumbres, Edición de Roberto R. Aramayo, Alianza Editorial, Madrid.

Kant, I. (2001) La Religión dentro de los límites de la mera Razón, Alianza Editorial, Madrid.

Kant, I. (2000) Lecciones sobre la filosofía de la religión, Ediciones Akal, Madrid.

Sánchez, J. (2003) Filosofía y Fenomenología de la Religión, Ediciones Secretariado Trinitario, Salamanca.

Torreti, R. (1980) Manuel Kant, Estudios sobre los fundamentos de la filosofía crítica, Editorial Charcas, Buenos Aires.

Wood, A. (1999) Kant's ethical thought, Cambridge University Press. 